\title{
Association of Borderline Intellectual Functioning and Adverse Childhood Experience with adult psychiatric morbidity. Findings from a British birth cohort
}

Angela Hassiotis ${ }^{1,2^{*}}$ (D) Emma Brown ${ }^{1}$, James Harris ${ }^{3}$, David Helm ${ }^{4}$, Kerim Munir ${ }^{4,5}$, Luis Salvador-Carulla ${ }^{6}$, Marco Bertelli ${ }^{7}$, Amaria Baghdadli ${ }^{8}$, Jannelien Wieland ${ }^{9}$, Ramon Novell-Alsina ${ }^{10}$, Jordi Cid $^{10}$, Laura Vergés ${ }^{10}$, Rafael Martínez-Leal ${ }^{11}$, Tuba Mutluer ${ }^{12}$, Fuad Ismayilov ${ }^{13}$ and Eric Emerson ${ }^{14}$

\begin{abstract}
Background: To examine whether Borderline Intellectual Functioning (BIF) and Adverse Childhood Experiences independently predict adult psychiatric morbidity.

Methods: We performed a secondary analysis of longitudinal data derived from the 1970 British Birth Cohort Study to examine whether BIF and Adverse Childhood Experiences independently predict adult mental distress as measured by the Malaise Inventory. Factor analysis was used to derive a proxy measure of IQ from cognitive testing at age 10 or 5. Variables that could be indicators of exposure to Adverse Childhood Experiences were identified and grouped into health related and socio-economic related adversity.
\end{abstract}

Results: Children with BIF were significantly more likely than their peers to have been exposed to Adverse Childhood Experiences (BIF mean 5.90, non-BIF mean 3.19; Mann-Whitney $z=31.74, p<0.001$ ). As adults, participants with BIF were significantly more likely to score above the cut-off on the Malaise Inventory. We found statistically significant relationships between the number of socio-economic Adverse Childhood Experiences and poorer adult psychiatric morbidity ( $r$ range 0.104-0.141, all $p<001$ ). At all ages the indirect mediating effects of Adverse Childhood Experiences were significantly related to adult psychiatric morbidity.

Conclusions: The relationship between BIF and adult psychiatric morbidity appears to be partially mediated by exposure to Adverse Childhood Experiences. Where possible, targeting Adverse Childhood Experiences through early detection, prevention and interventions may improve psychiatric morbidity in this population group.

Keywords: Borderline, Intellectual, Adversity, Mental wellbeing, Childhood

\section{Background}

Exposure to Adverse Childhood Experiences (ACEs) represents a significant threat to the health and wellbeing of children. A broad definition of ACEs encompasses events occurring in a child's family or social environment that may cause harm or distress. This includes proximal traumatic events (e.g. physical, verbal or sexual

\footnotetext{
* Correspondence: a.hassiotis@ucl.ac.uk

'Division of Psychiatry, University College London, 149 Tottenham Court Road, London W1T 7NF, UK

${ }^{2}$ Camden \& Islington Foundation Trust, St Pancras Hospital, London, UK Full list of author information is available at the end of the article
}

abuse) and problematic aspects of family functioning (e.g. parental domestic violence, substance abuse or separation, household poverty). ACEs impact a great number of the general population, with evidence suggesting that $57 \%$ of children have experienced one or more ACEs [1].

Exposure to ACEs has been associated with negative health consequences in later life, such as diabetes, cardiovascular problems and cancer [2-4] and is also thought to impact adult mental health. Hughes et al. [1] showed that those who have experienced four or more ACEs were around four times more likely to experience

(c) The Author(s). 2019 Open Access This article is distributed under the terms of the Creative Commons Attribution 4.0 International License (http://creativecommons.org/licenses/by/4.0/), which permits unrestricted use, distribution, and 
adult mental distress. Those who have experienced ACEs have increased rates of psychiatric disorders, including depression, anxiety, Post Traumatic Stress Disorder (PTSD), schizophrenia, substance dependence, self-harm and suicide attempts [5-7]. This relationship has been replicated across high, middle and low income countries around the world [8]. More specifically, there is strong evidence indicating a link between low socioeconomic status in childhood and adult mental health, with the type and duration of socioeconomic adversity in childhood predicting the onset, duration and severity of adult mental health disorders [8-10].

Research has shown that children with intellectual impairments are at greater risk of being exposed to ACEs compared with their peers. Children with intellectual disability are between three and seven times more likely to experience neglect, physical, emotional and sexual abuse and experience a broader range of ACEs compared to other children [11-13]. They also have higher rates of mental health problems across the lifespan [1417].

People labelled with Borderline intellectual functioning (BIF) typically score lower on tests of intellectual ability and other indices of cognitive functioning than the general population, but not to the extent to be defined as an intellectual disability. BIF does not present with a specific symptom or set of symptoms but as a continuum of risk across the lifespan. The closer the proximity to Intellectual Disability, or greater the degree of cognitive and adaptive impairments, the higher the likelihood of associated risks that need to be monitored throughout development in order to encourage better coping strategies and healthy behaviours.

When considering Intelligence Quotient (IQ), BIF is commonly defined as between one and two standard deviations below the mean on standardised tests of intelligence, (IQ range 70-85). Therefore, according to the normally distributed curve of IQ, the range spans the 2nd to the 16th percentile, including $14 \%$ of the population [18]. It is not clear whether BIF should be regarded as a risk factor, as a dimensional health condition or as a category within the developmental disorders. BIF was not included in DSM-5 [19] as a neurodevelopmental disorder (F code) diagnosis but it is listed in both DSM-5 and the US ICD-10-CM [20] among "Other Conditions That May Be a Focus of Clinical Attention" (R41.83).

Policy changes and societal attitudes towards those with intellectual impairments have contributed to lack of awareness and neglect of people with BIF. It often goes unrecognised by health or social care professionals, who do not receive routine training in the identification of BIF or in adapting interventions to address their cognitive needs, resulting in inappropriate or lack of formal support [21, 22]. The lack of attention given to BIF persists not only through professional services but through research, with comparatively little interest in investigating this group [23].

Despite the lack of clarity around definition and recognition, individuals with BIF as a group are particularly at risk. The literature shows that adults with BIF have higher rates of incarceration, job insecurity, drug use and poor social functioning and are over twice as likely to have a psychiatric diagnosis as people with an average or above IQ [24-26]. This association has been found for depression, anxiety disorders, post-traumatic stress disorder, psychosis, substance abuse, personality disorders, self reported suicide attempts and neurodevelopmental disorders [27-33].

There is indication that those with BIF are also at greater risk of early life stressors. Children with BIF are more likely to experience bullying, poor parenting, poverty, material hardship and parental unemployment than typically developing children [34-37]. Interestingly, Emerson et al. [37] replicated findings that children with BIF had an increased risk of mental health problems, but found that when the confounding effect of exposure to socio-economic disadvantage was controlled for, the higher prevalence of mental health problems was greatly reduced. This prompts questions regarding the mediating effect that childhood experiences may have on the mental health of adults with BIF.

Most published studies of the impact of ACE on children or adults use cross-sectional samples. In the current paper we used a longitudinal cohort from the UK to investigate 1) the association between BIF and adult psychiatric morbidity; 2) the association between BIF and exposure to ACEs; 3) the extent to which exposure to ACEs moderates and/or mediates the association between BIF and adult psychiatric morbidity. We hypothesised that children with BIF would have greater exposure to ACEs than their typically developing peers, and that this exposure to ACEs would partially mediate the higher rates of adult psychiatric morbidity.

\section{Method}

The study is based on a secondary analysis of data from six waves of the 1970 British Cohort Study (BCS70). BCS70 is following up over 17,000 children born during one week in the UK in 1970, with data collected soon after birth (first wave) $[38,39]$. Since then, additional waves have taken place in at age $5(n=12,939), 10(n=$ $14,350), 16(n=11,206), 26(n=8654), 30(n=10,833)$, $34(n=9316), 38(n=8874)$ and $42(n=9717)$ years [4042]. The surveys cover health status; health behaviours; wellbeing; educational attainment; employment and occupation; financial status; social and civic participation; social support; family formation and crime. Anonymised 
data from ages $5,10,26,30,34$ and 42 follow-up surveys were downloaded from the UK Data Service for this study [43-48].

\section{Identifying participants with borderline intellectual functioning}

While BCS70 includes measures of child cognitive functioning at ages 5 and 10 [49], these were not validated IQ tests but instead, a range of brief tests drawn from existing IQ tests were administered, or tests of assessed attainment that is likely to be related to IQ. In this study, we have followed established procedures in deriving a proxy [49-51].

At age 10, eight tests were administered: the Shortened Edinburgh Reading Test [52]; the Friendly Maths Test [49]; the Pictorial Language Comprehension Test [49]; the Spelling Dictation task [49]; and four subscales of the British Ability Scales, Word Definitions, Word Similarities, Recall of Digits and Matrices [53]. In total, 12, 885 (87\%) of children participating at age 10 completed at least one assessment; 11,134 (75\%) children completed all assessments [49].

Cognitive test results at age 5 were available for an additional 2568 children who, however, did not have test results reported at age 10 . At age 5 , the children were administered: the Copying Designs Test [54]; the English Picture Vocabulary Test [55]; the Human Figure Drawing (Draw-a-Person) Test [56]; the Complete a Profile Test [57]; and the Schonell Reading Test [58]. In total, $13,059(99 \%)$ of all children participating in the age 5 survey completed at least one assessment and 11,254 (86\%) children completed all assessments [49].

\section{Childhood adversities}

Data collected at age 5 and age 10 follow-ups were reviewed to identify variables that indicated exposure to low socio-economic position and specific adverse childhood experiences as included in a recent systematic review [1]. We identified 25 variables (13 at age 10, 12 at age 5). Of these, 19 were based on 11 indicators of social and/or material deprivation (living in a poor area, living in damp housing, living in overcrowded housing, living in rented housing, low parental educational attainment, low social class, low household assets, low income, living in a workless household, living in a single parent family, potential maternal psychiatric morbidity). All but three of these (living in damp housing, living in overcrowded housing, low income) were collected at ages 5 and 10 . The remaining six indicators related to three healthrelated adversities (accident requiring medical treatment, hospital out-patient attendance at ages, hospital inpatient admission) each collected at ages 5 and 10. Initial inspection of these data indicated that the indicators based on social and/or material deprivation performed well as a simple additive scale (alpha $=0.80)$, but inclusion of the indicators based on health-related adversities significantly reduced the scale's internal consistency. As a result, we created a separate additive scale for health related adversities $($ alpha $=0.53)$.

\section{Adult psychiatric morbidity}

At ages 26 and 30 the 24-item self-completed Malaise Inventory was used to measure levels of anxiety and/or depression, with potential adult psychiatric morbidity being identified by a score of eight or more [59]. At ages 34 and 42 an abbreviated 9-item version of the Malaise Inventory was used, with a potential mental health problem being identified by a score of four or more.

\section{Statistical analysis}

In order to maximise use of participants' data and to reduce potential bias resulting from exclusion of partial non-respondents, missing cognitive test data for partial respondents were imputed using multiple imputation routines in IBM SPSS 22. Five parallel data sets were imputed and then averaged to create the final imputed data.

Principal components analysis was used to establish the presence of a general cognitive ability factor across tests and standardised scores on the first component were extracted as a proxy indicator for IQ [49-51]. At age 10, the first extracted component accounted for $59 \%$ of the variance of initial eigenvalues with all tests loading positively on the component (loading range 0.55-0.88). For the respondents with missing data on cognitive testing at age 5 we followed the procedures outlined above to: (1) impute partially missing cognitive test results; (2) establish the presence of a general cognitive ability factor across tests $(g)$; (3) use standardised scores on $g$ as an indicator of IQ at age 5. At age 5, the first extracted component accounted for $41 \%$ of the variance of initial eigenvalues with all tests loading positively on the component (loading range $0.47-0.76$ ).

Exploratory analyses indicated significantly higher attrition rates among participants with BIF than those without BIF. We addressed attrition by imputing missing data (arising from either wave or item non-response) as previous analyses of $\mathrm{BCS} 70$ had indicated that imputation models were preferable to the use of sample weights [60]. We used sex, BIF status, child behaviour problems at ages 5 and 10 and available responses to the Malaise Inventory at ages 26, 30, 34 and 42 to impute missing adult mental health data.

Firstly, we used simple descriptive statistics to characterise the associations between: (1) BIF and exposure to childhood adversities; and (2) exposure to childhood adversities and adult mental health. 
Second, we estimated the strength of association between BIF and adult mental health in four models. In Model 1 we reported unadjusted prevalence rate ratios (with 95\% confidence intervals) for adult mental health problems among participants with BIF (participants without BIF being the reference group). In Model 2 we estimated prevalence rate ratios for adult mental health problems among participants with BIF adjusted for between group differences in participant gender as initial exploratory analysis indicated that BIF was more common among males (14.3\% vs. $12.9 \%)$. In Model 3 we estimated prevalence rate ratios for adult mental health problems among participants with BIF adjusted for between group differences in participant gender and exposure to childhood adversities. For these analyses we recoded the number of adversities into population-based quintiles. In Model 4, we included BIF"childhood adversities interaction terms into the model to estimate whether BIF status moderated the association between exposure to childhood adversities and adult mental health problems. Prevalence rate ratios were estimated using Poisson regression with robust standard errors [61, 62] using fully imputed datasets and datasets in which missing data on adult mental health outcomes were not imputed. We primarily report analyses using fully imputed datasets, with comments on any notable variation between analyses conducted with the imputed and non-imputed data.

\section{Results}

Of the 15,453 participants, $426(2.8 \%)$ were functioning in the IQ range associated with intellectual disability (IQ
70 or below), 2108 (13.6\%) were functioning in the BIF range (IQ range 71-85) and 12,919 (83.6\%) were functioning in a higher IQ range (IQ 86+).

Children with BIF were significantly more likely than their peers to have experienced childhood adversities related to social and/or material deprivation (number of adversities: BIF mean 5.90 median 6; non-BIF mean 3.19 median 2, Mann-Whitney $\mathrm{z}=31.74, p<0.001)$ and childhood adversities related to health events (number of adversities: BIF mean 2.45 median 2, non-BIF mean 2.15 median 2, Mann-Whitney $\mathrm{z}=7.14, p<0.001$ ). The proportional frequency distribution of exposure to adversities related to social and/or material deprivation is shown in Fig. 1.

At all adult ages there were statistically significant relationships between the number of socio-economic adversities exposed to in childhood and higher Malaise Inventory scores for participants with BIF (Spearman's $\mathrm{r}$ range 0.09-0.14, all $p<0.001$ ) and without BIF (Spearman's $r$ range $0.08-0.12$, all $p<0.001$ ). Example data are provided in Fig. 2. For participants with BIF there were no statistically significant relationships between the number of health adversities in childhood and higher adult Malaise Inventory scores at any age. For participants without BIF only at age 34 was there a statistically significant relationships between the number of health adversities in childhood and higher adult Malaise Inventory scores $(\mathrm{r}=0.02, p<0.05)$.

Unadjusted prevalence rates and unadjusted and adjusted prevalence rate ratios are presented in Table 1 for fully imputed data and in Table 2 for data in which only the predictor variables were imputed. In the fully

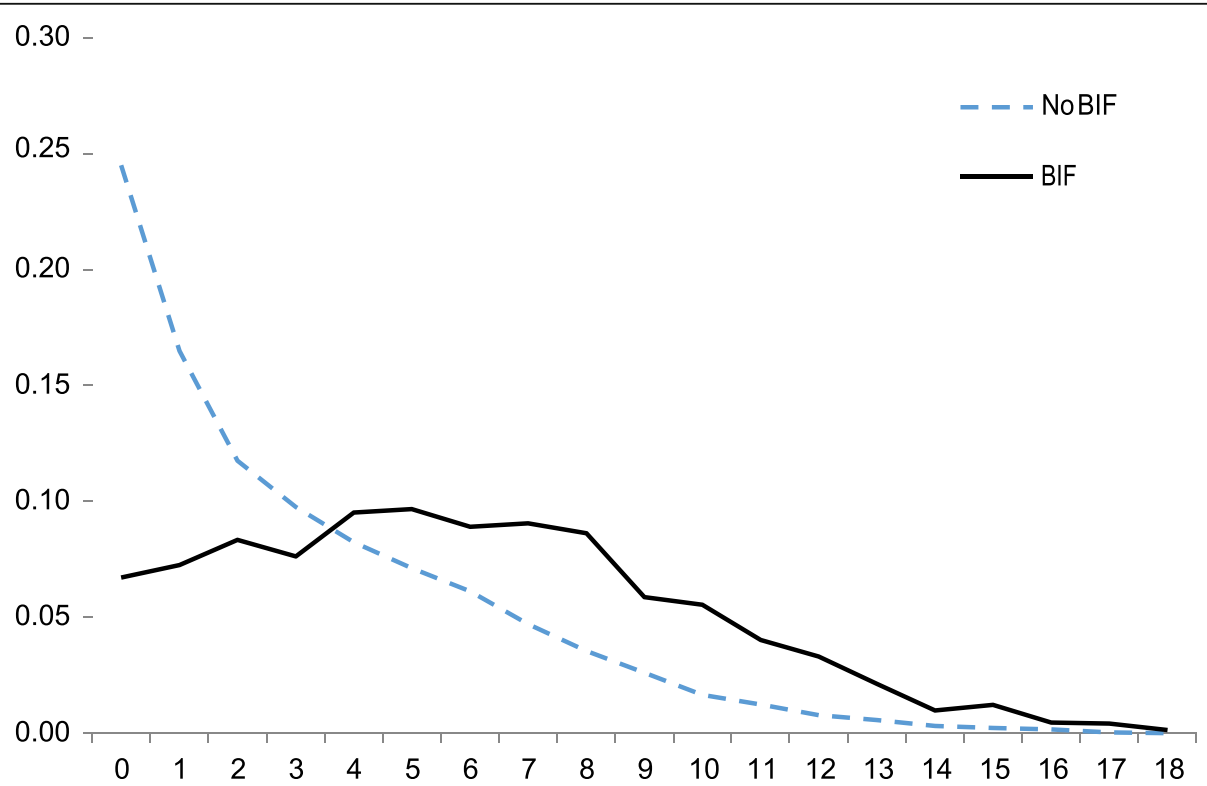

Fig. 1 Proportional frequency distribution of exposure to ACEs for children with and without borderline intellectual functioning 


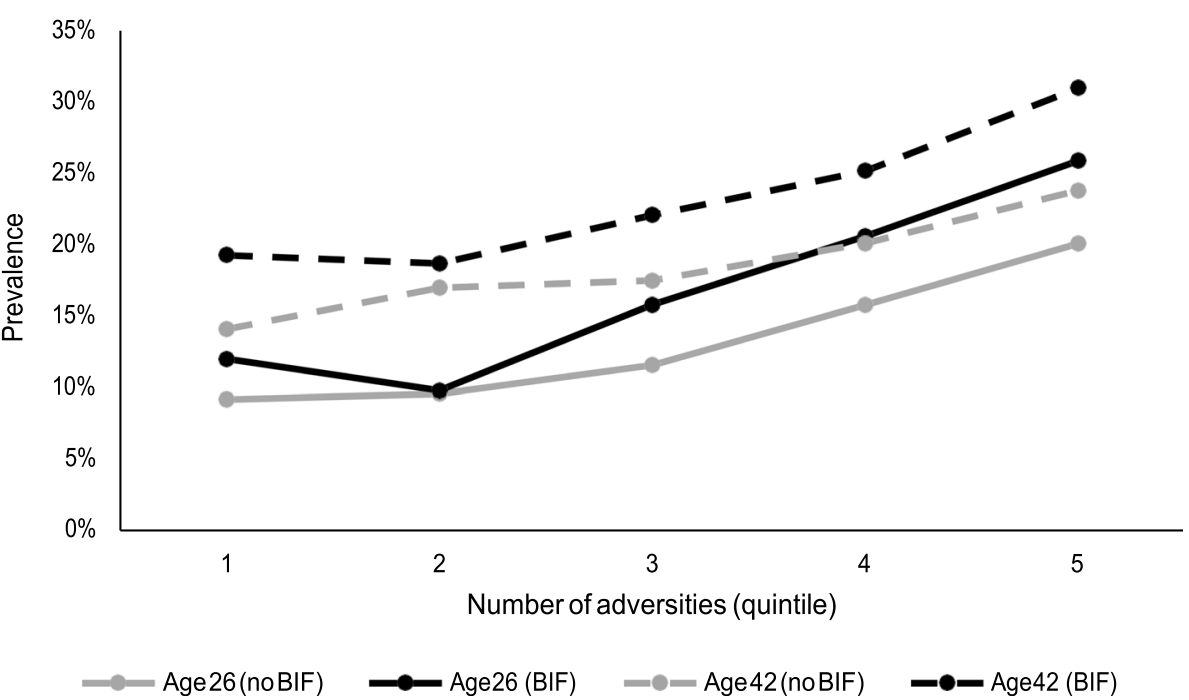

Fig. 2 Association between exposure to childhood adversities associated with material and/or social deprivation and adult psychiatric morbidity at ages 26 and 42 for participants with and without BIF

imputed data there were highly significant differences in unadjusted prevalence rate ratios for possible adult psychiatric morbidity between participants with and without BIF at all ages. Adjusting these ratios for between-group differences in gender (Model 2) marginally increased the prevalence rate ratios at all ages. Further adjusting these ratios for between-group differences in exposure to childhood adversities (Model 3) significantly reduced the prevalence rate ratios at all ages. The percentage reduction in risk evident for possible adult psychiatric morbidity among participants with BIF in Model 3 raged from $51 \%$ at age 26 to $24 \%$ at age 42 . Risk attenuation in Model 3 reflected the increased risk of participants with BIF being exposed to childhood adversities associated with material and/or social deprivation. Exposure to health-related adversities did not significantly contribute to Model 3 results at any age. Assuming Type 1 and Type 2 error rates of 0.05 , the sample size of participants with BIF is greater than needed to detect a correlation coefficient greater than 0.08 and the sample size of participants without BIF is greater than needed to detect a correlation coefficient greater than 0.04 . There was no evidence of effect modification of exposure to childhood adversities associated with material and/or social deprivation by BIF status at any age.

Analyses which did not involve the imputation of dependent variables showed a very similar pattern (Table 2). The key differences are: (1) notable lower

Table 1 Prevalence and prevalence rate ratios of potential mental health problems. in adulthood by borderline intellectual functioning status and age (fully imputed data).

\begin{tabular}{|c|c|c|c|c|}
\hline & Age 26 & Age 30 & Age 34 & Age 42 \\
\hline Borderline intellectual functioning prevalence (with 95\% CI) & $\begin{array}{l}20.7 \%(17.1- \\
24.8 \%)\end{array}$ & $\begin{array}{l}20.8 \%(17.2- \\
24.9 \%)\end{array}$ & $\begin{array}{l}23.5 \%(19.7- \\
27.8 \%)\end{array}$ & $\begin{array}{l}26.2 \%(22.2- \\
30.6 \%)\end{array}$ \\
\hline Higher estimated IQ prevalence (with 95\% Cl) & $\begin{array}{l}12.9 \%(12.3- \\
13.5 \%)\end{array}$ & $\begin{array}{l}11.5 \%(11.0- \\
12.1 \%)\end{array}$ & $\begin{array}{l}15.0 \%(14.4- \\
15.6 \%)\end{array}$ & $\begin{array}{l}18.2 \%(17.5- \\
18.9 \%)\end{array}$ \\
\hline Model 1: Unadjusted prevalence rate ratio (with 95\% Cl) & $\begin{array}{l}1.60(1.45- \\
1.76)\end{array}$ & $\begin{array}{l}1.81(1.64- \\
1.99)\end{array}$ & $\begin{array}{l}1.57(1.44- \\
1.71)\end{array}$ & $\begin{array}{l}1.45(1.33- \\
1.56)\end{array}$ \\
\hline$P$ value & $<0.001$ & $<0.001$ & $<0.001$ & $<0.001$ \\
\hline Model 2: Prevalence rate ratio adjusted for participant gender & $\begin{array}{l}1.63(1.48- \\
1.79)\end{array}$ & $\begin{array}{l}1.83(1.67- \\
2.02)\end{array}$ & $\begin{array}{l}1.64(1.50- \\
1.78)\end{array}$ & $\begin{array}{l}1.46(1.35- \\
1.58)\end{array}$ \\
\hline$P$ value & $<0.001$ & $<0.001$ & $<0.001$ & $<0.001$ \\
\hline $\begin{array}{l}\text { Model 3: Prevalence rate ratio adjusted for participant gender and exposure to } \\
\text { childhood adversities }\end{array}$ & $\begin{array}{l}1.31(1.19- \\
1.45)\end{array}$ & $\begin{array}{l}1.53(1.38- \\
1.69)\end{array}$ & $\begin{array}{l}1.35(1.23- \\
1.47)\end{array}$ & $\begin{array}{l}1.35(1.25- \\
1.47)\end{array}$ \\
\hline$P$ value & $<0.001$ & $<0.001$ & $<0.001$ & $<0.001$ \\
\hline $\begin{array}{l}\text { Model 4: Significance of BIF status by childhood adversities associated with material } \\
\text { and/or social deprivation }\end{array}$ & n.s & n.s & n.s & n.s \\
\hline
\end{tabular}


Table 2 Prevalence and prevalence rate ratios of potential mental health problems.in adulthood by borderline intellectual functioning status and age (only childhood adversity imputed).

\begin{tabular}{|c|c|c|c|c|}
\hline & Age 26 & Age 30 & Age 34 & Age 42 \\
\hline Borderline intellectual functioning prevalence (with 95\% Cl) & $\begin{array}{l}17.0 \%(14.5- \\
19.8 \%)\end{array}$ & $\begin{array}{l}16.7 \%(14.5- \\
19.8 \%)\end{array}$ & $\begin{array}{l}19.6 \%(17.2- \\
22.2 \%)\end{array}$ & $\begin{array}{l}22.0 \%(19.3- \\
25.0 \%)\end{array}$ \\
\hline Higher estimated IQ prevalence (with 95\% Cl) & $\begin{array}{l}12.7 \%(11.9- \\
13.5 \%)\end{array}$ & $\begin{array}{l}11.6 \%(10.9- \\
12.3 \%)\end{array}$ & $\begin{array}{l}14.4 \%(13.6- \\
15.2 \%)\end{array}$ & $\begin{array}{l}17.6 \%(16.6- \\
18.5 \%)\end{array}$ \\
\hline Model 1: Unadjusted prevalence rate ratio (with 95\% Cl) & $\begin{array}{l}1.34(1.13- \\
1.59)\end{array}$ & $\begin{array}{l}1.44(1.25- \\
1.66)\end{array}$ & $\begin{array}{l}1.36(1.18- \\
1.57)\end{array}$ & $\begin{array}{l}1.26(1.09- \\
1.45)\end{array}$ \\
\hline$P$ value & $<0.01$ & $<0.001$ & $<0.001$ & $<0.01$ \\
\hline Model 2: Prevalence rate ratio adjusted for participant gender & $\begin{array}{l}1.37(1.16- \\
1.61)\end{array}$ & $\begin{array}{l}1.45(1.26- \\
1.68)\end{array}$ & $\begin{array}{l}1.38(1.20- \\
1.59)\end{array}$ & $\begin{array}{l}1.26(1.09- \\
1.45)\end{array}$ \\
\hline$P$ value & $<0.001$ & $<0.001$ & $<0.001$ & $<0.01$ \\
\hline $\begin{array}{l}\text { Model 3: Prevalence rate ratio adjusted for participant gender and exposure to } \\
\text { childhood adversities }\end{array}$ & $\begin{array}{l}1.12(0.94- \\
1.32)\end{array}$ & $\begin{array}{l}1.21(1.04- \\
1.40)\end{array}$ & $\begin{array}{l}1.17(1.01- \\
1.35)\end{array}$ & $\begin{array}{l}1.10(0.95- \\
1.27)\end{array}$ \\
\hline$P$ value & n.s. & $<0.05$ & $<0.05$ & n.s. \\
\hline $\begin{array}{l}\text { Model 4: Significance of BIF status by childhood adversities associated with material } \\
\text { and/or social deprivation }\end{array}$ & n.s & n.s & n.s & n.s \\
\hline
\end{tabular}

Notes: $\mathrm{Cl}=$ Confidence interval, n.s. $=$ not significant at alpha $p<0.05$

prevalence estimates for possible adult mental health problems, especially among participants with BIF; (2) notable lower prevalence rate ratios for possible adult mental health problems among participants with BIF at all ages; (3) Model 3 adjustments reducing the statistical significance of increased risk for possible adult mental health problems among participants with BIF to nonsignificant levels at ages 26 and 42 .

\section{Discussion}

This study is the first, to our knowledge, to take a longitudinal approach in examining the association between BIF and adult psychiatric morbidity and its association with ACEs. It is the strongest evidence yet that children with BIF are at greater risk of exposure to ACEs than their peers.

More work needs to be done to fully clarify the causal mechanisms underlying the association between BIF and ACEs. Previous research by Chen et al. reported higher mental health problems among children with IQ scores between 70 and 80 (in the BIF range) compared to those with IQ scores below 70 [63]. This finding was consistent with prior concept that the BIF group may be sensitive enough to understand age or role appropriate expectations and may be frustrated by not being able to reach these levels without recourse to professional support for which they may not be eligible [64].

The long-term effects of ACEs may also exacerbate cognitive sets and shape negative styles of interpersonal interactions and relationships [65]. Another consideration is that effects of ACE in early life may lead to functional and structural changes in the neuroendocrine system [66] with consequent impact on mental health. A counter-point is that coexistence of BIF, ACEs and adult psychiatric morbidity implies that the association does not represent environmentally mediated risk processes since risk experiences are not randomly distributed and may, in part, reflect genetic mediation [67].

\section{Strengths and limitations}

This is the largest population-based study to examine associations between BIF, ACEs and adult psychiatric morbidity. It demonstrates, using a longitudinal analysis, that effects of ACEs are exaggerated in individuals with BIF and that their coexistence may play a contributory role in the onset of adult mental disorders.

However, our study has a number of limitations. First, the interpretation of the findings is hindered by the use of the Malaise Inventory which has not been validated as a screening or diagnostic test for mental disorders in general. However, the scale has shown moderate validity against psychiatric morbidity [59] and acceptable psychometric properties [68]. It has been used across population groups, including high risk groups $[69,70]$ and the abbreviated 9-item subscale has gone on to be used in other cohort studies [71, 72].

Second, the indicators of ACE in the present study were primarily based on measures of socioeconomic position rather than child maltreatment, domestic violence or victimization. Nonetheless, the probability of exposure to these more proximal risk factors is significantly greater for children in low socioeconomic position families [11, 73].

Third, child IQ was derived by proxy from cognitive test scores, however the sensitivity and specificity of our proxy measure is unknown. When using proxy measures of IQ, it is possible that at the tails of the IQ distribution in low functioning individuals may be over or under 
estimated thus leading to inaccuracies in prevalence rates [74].

Fourth, there has been significant attrition at the survey follow up points. Multiple imputation has been shown to be effective in reducing the bias resulting from missing items when the magnitude of the bias is high and the imputation models are well specified. However, we cannot be certain to have eliminated all sources of bias [75].

\section{Implications for future research}

The findings highlight the complex association between BIF, ACEs and future psychiatric morbidity and the need for further research in this area. Shonkoff, Boyce and McEwen [76] argue that disorders in adulthood often have their origins in disruptions in childhood developmental processes mainly due to biological insults that can manifest many years later. Therefore, study of such processes may encourage earlier intervention with greater certainty than currently exists.

Achievable practical objectives could include: strengthening child protection procedures to reduce risk of exposure to ACEs; increasing awareness and inclusion of questions about intellectual impairment in diagnostic interviews in primary and secondary care; identification of ACEs which should alert health and social care professionals about the potential of the presence of BIF in the index child, leading to follow up assessments or specialist referrals.

It is of concern that the visibility of BIF may decrease further as this condition has been excluded from the new version of the WHO International Classification of Diseases (ICD-11). Paradoxically, though, there is a growing interest on the topic by some public agencies and governments [77]. Our results, clearly accord with previous research that shows the detrimental impact of socio-economic disadvantage mainly in children with intellectual disabilities $[78,79]$ who are also more likely to experience bullying, neglect and emotional, sexual, physical abuse [78]. Building international consensus on the BIF [80] may not only increase awareness but also encourage development of interventions and the reexamination of its diagnostic utility.

\section{Conclusions}

Whilst low IQ can be seen as an ACE itself, the strength of the study is that it has improved on previous research [81], by the fact that the present longitudinal data were collected prospectively rather than retrospectively. BIF is a little understood entity and often subsumed within a wider "normal" range of ability and functioning. This leads many children, young people and adults to fall outside statutory services and they are, therefore, unable to receive specialist support. By bringing the issue to light, it is our hope that not only we will promote interdisciplinary collaboration and raise awareness but also foster interest in developing preventive and remedial interventions at population and individual level to combat ACEs to improve child and family welfare.

\section{Abbreviations}

ACEs: Adverse Childhood Experiences; BCS70: 1970 British Cohort Study; BIF: Borderline intellectual functioning; DSM: Diagnostic and Statistical Manual; ICD: International Classification of Diseases; IQ: Intelligence Quotient; PTSD: Post Traumatic Stress Disorder

\section{Acknowledgements}

We thank the Centre for Longitudinal Studies, Institute of Education, University of London, UK for permission to use the relevant British Cohort Study 1970 data.

\section{Authors' contributions}

The discussion about the study took place at an international meeting in Girona, Spain in May 2017. All authors except EB (AH, EE, LS-C, KM, JH, MB, $J W, A B, R N-A, D H, J C, R M-L, T M$ and $F I$ ) were present and contributed to the idea and work plan. EE carried out the analysis of the data, $A H$ and $E B$ drafted and revised the manuscript incorporating the comments from the co-authors through an iterative process. All authors read and approved the final manuscript.

\section{Funding}

The BIF Consensus Group was sponsored by the Institut d'Assistència Sanitària, the Government of Catalunya (RN-A, LV, JC), the NCD-Lifespan (TW98045) and Global RD0C (TW009680) Fogarty/NIMH grants at the Boston Children's Hospital, Harvard Medical School (K Munir), and the Mental Health Policy Unit, the Centre for Disability Research and Policy Faculty of Health Sciences, University of Sydney (L Salvador-Carulla, E Emerson). The funding body did not have any part in the design of the study, the analysis and interpretation of data and in writing the manuscript

\section{Availability of data and materials}

This is publicly archived dataset based at the Centre for Longitudinal Studies, UCL. Anonymised data are available to download from the UK Data Service. The datasets generated and/or analysed during the current study are available in the https://cls.ucl.ac.uk/cls-studies/1970-british-cohort-study/

Ethics approval and consent to participate

NHS Research Ethics Committees ethical approval was sought and granted for BCS70 follow-ups from 2000 onwards.

Consent for publication

Not applicable.

\section{Competing interests}

Author Luis Salvador-Carulla is currently acting as a Guest Editor for BMC Psychiatry; all other authors have nothing to declare.

\section{Author details}

${ }^{1}$ Division of Psychiatry, University College London, 149 Tottenham Court Road, London W1T 7NF, UK. ${ }^{2}$ Camden \& Islington Foundation Trust, St Pancras Hospital, London, UK. ${ }^{3}$ Developmental Neuropsychiatry, Department of Psychiatry and Behavioral Sciences, Bloomberg Children's Center, The Johns Hopkins Hospital, Baltimore, MD, USA. ${ }^{4}$ Institute for Community Inclusion, Division of Developmental Medicine, Boston Children's Hospital, Boston, MA, USA. ${ }^{5}$ Developmental Medicine Center, Division of Developmental Medicine, Boston Children's Hospital and Harvard Medical School, Boston, MA, USA. ${ }^{6}$ Centre for Mental Health Research, Australian National University, Acton, Australia. ${ }^{7}$ CREA, Research and Clinical Centre, San Sebastiano Foundation, Florence, Italy. ${ }^{8} \mathrm{Child}$ and Adolescent Psychiatry Department, Montpellier Hospital University, Montpellier, France. ${ }^{9}$ Kristal Centre for Psychiatry and Intellectual Disability, Rivierduinen, Leiden, The Netherlands. ${ }^{10}$ Mental Health and Intellectual Disability Specialized Service, Catalan Health Govenment. Martí i Julià Hospital, Girona, Spain. ${ }^{11}$ Intellectual Disability and Developmental Disorders Research Unit (UNIVIDD), Fundació 
Villablanca, IISPV, Universitat Rovira i Virgili, CIBERSAM, Reus, Spain. ${ }^{12}$ Department of Child and Adolescent Psychiatry, Koc University Hospital, Istanbul, Turkey. ${ }^{13}$ Department of Psychiatry, Azerbaijan Medical University, Baku, Azerbaijan. ${ }^{14}$ Centre for Disability Research \& Policy, Faculty of Health Sciences, University of Sydney, Sydney, Australia.

Received: 17 June 2019 Accepted: 27 November 2019

Published online: 05 December 2019

\section{References}

1. Hughes $K$, Bellis MA, Hardcastle KA, Sethi D, Butchart A, Mikton C, Jones L, Dunne MP. The effect of multiple adverse childhood experiences on health: a systematic review and meta-analysis. Lancet Public Health. 2017;2(8):35666.

2. Monnat SM, Chandler RF. Long-term physical health consequences of adverse childhood experiences. Sociol Q. 2015;56(4):723-52

3. Brown DW, Anda RF, Felitti VJ, Edwards VJ, Malarcher AM, Croft JB, Giles WH. Adverse childhood experiences are associated with the risk of lung cancer: a prospective cohort study. BMC Public Health. 2010;10:20.

4. Brown DW, Anda RF, Tiemeier H, Felitti VJ, Edwards VJ, Croft JB, Giles WH. Adverse childhood experiences and the risk of premature mortality. Am J Prev Med. 2009:37(5):389-96

5. Kalmakis KA, Chandler GE. Health consequences of adverse childhood experiences: a systematic review. J Am Assoc Nurse Pract. 2015;27(8): 457-65.

6. Baiden P, Stewart SL, Fallon B. The role of adverse childhood experiences as determinants of non-suicidal self-injury among children and adolescents referred to community and inpatient mental health settings. Child Abuse Negl. 2017;69:163-76.

7. Fuller-Thomson E, Baird SL, Dhrodia R, Brennenstuhl S. The association between adverse childhood experiences (ACEs) and suicide attempts in a population-based study. Child Care Health Dev. 2016;42(5):725-34.

8. Kessler RC, McLaughlin KA, Green JG, et al. Childhood adversities and adult psychopathology in the WHO world mental health surveys. Br J Psychiatry. 2010;197(5):378-85.

9. McLaughlin KA, Breslau J, Green JG, Lakoma MD, Sampson NA, Zaslavsky AM, Kessler RC. Childhood socio-economic status and the onset, persistence, and severity of DSM-IV mental disorders in a US national sample. Soc Sci Med. 2011;73(7):1088-96.

10. Ochi M, Fujiwara T, Mizuki R, Kawakami N. Association of socioeconomic status in childhood with major depression and generalized anxiety disorder: results from the world mental health Japan survey 2002-2006. BMC Public Health. 2014;14:359. https://doi.org/10.1186/1471-2458-14-359.

11. Emerson E, Spencer N. Health inequity and children with intellectual disabilities. In: Hatton C, Emerson E, editors. International review of research in developmental disabilities, 48. New York: Elsevier; 2015. p. 11-42.

12. Spencer N, Devereux E, Wallace A, Sundrum R, Shenoy M, Bacchus C, Logan S. Disabling conditions and registration for child abuse and neglect: a population based study. Pediatrics. 2005;116(3):609-13.

13. Hatton C, Emerson E. The relationship between life events and psychopathology amongst children with intellectual disabilities. J Appl Res Intellect Disabil. 2004;17(2):109-17.

14. Cooper S-A, Smiley E, Morrison J, Allan L, Williamson A. Prevalence of and associations with mental ill-health in adults with intellectual disabilities. $\mathrm{Br} J$ Psychiatry. 2007;190(1):27-35

15. Cooper S-A, Smiley E, Finlayson J, Jackson A, Allan L, Williamson A, Mantry $D$, Morrison J. The prevalence, incidence, and factors predictive of mental illhealth in adults with profound intellectual disabilities. J Appl Res Intellect Disabil. 2007;20(6):493-501.

16. Hassiotis A, Turk J. Mental health needs in adolescents with intellectual disabilities: cross-sectional survey of a service sample. J Appl Res Intellect Disabil. 2012;25:252-61

17. Strydom A, Hassiotis A, Livingston G. Mental health and social care needs of older people with intellectual disabilities. J Appl Res Intellect Disabil. 2005; 18(3):229-35.

18. Greenspan S. Borderline intellectual functioning: an update. Curr Opin Psychiatry. 2017;30(2):113-22

19. American Psychiatric Association. The diagnostic and statistical manual of mental disorders:DSM-5. 5th ed. Washington: American Psychiatric Association; 2013.
20. National Center for Health Statistics (2018) International classification of diseases, 10th revision, clinical modification (ICD-10-CM). Centers for Disease Control and Prevention.

21. Fernell $E, E k U$. Borderline intellectual functioning in children and adolescents - insufficiently recognized difficulties. Acta Pediatrica. 2010; 99(5):748-53.

22. Nieuwenhuis JG, Noorthoorn EO, Nijman HLI, Naarding P, Mulder CL. A blind spot? Screening for mild intellectual disability and borderline intellectual functioning in admitted psychiatric patients: prevalence and associations with coercive measures. PLoS One. 2017;12(2):e0168847.

23. Peltopuro M, Ahonen T, Kaartinen J, Seppälä H, Närhi V. Borderline intellectual functioning: a systematic literature review. Intellect Dev Disabil. 2014:52(6):419-43.

24. Hayes S, Shackell P, Mottram P, Lancaster R. The prevalence of intellectual disability in a major UK prison. Br J Learn Disabil. 2007;35(3):162-7.

25. Emerson E, Hatton C, Robertson J, Baines S. The association between nonstandard employment, job insecurity and health among British adults with and without intellectual impairments: cohort study. SSM Popul Health. 2018; 4:197-205.

26. Gigi K, Werbeloff N, Goldberg S, Portuguese S, Reichenberg A, Fruchter E, Weiser M. Borderline intellectual functioning is associated with poor social functioning, increased rates of psychiatric diagnosis and drug use - a cross sectional population based study. Eur Neuropsychopharmacol. 2014;24(11): 1793-7.

27. Morgan V, Leonard H, Bourke J, Jablensky A. Intellectual disability cooccurring with schizophrenia and other psychiatric illness: population-based study. Br J Psychiatry. 2008;193(5):364-72.

28. Douma JC, Dekker MC, De Ruiter KP, Verhulst FC, Koot HM. Help-seeking process of parents for psychopathology in youth with moderate to borderline intellectual disabilities. J Am Acad Chld Adolesc Psychiatry. 2006; 45(10):1232-42.

29. Hassiotis A, Strydom A, Hall I, et al. Psychiatric morbidity and social functioning among adults with borderline intelligence living in private households. J Intellect Disabil Res. 2008:52:95-106.

30. Wieland J, Haan SK, Zitman FG. Psychiatric disorders in outpatients with borderline intellectual functioning: comparison with both outpatients from regular mental health care and outpatients with mild intellectual disabilities. Can J Psychiatr Rev Can Psychiatr. 2014;59(4):213-9.

31. Hassiotis A, Noor M, Bebbington P, Ali A, Wieland J, Qassem T. Borderline intellectual functioning and psychosis: adult psychiatric morbidity survey evidence. Br J Psychiatry. 2017;211(1):50-1.

32. Hassiotis A. Psychosocial intervention for adults with neurodevelopmental disorders and challenging behaviours: a synthesis of the literature. J Intellect Disabil Res. 2015;59:11-2.

33. Hassiotis A, Tanzarella M, Bebbington P, Cooper C. Prevalence and predictors of suicidal behaviour in a sample of adults with estimated borderline intellectual functioning: results from a population survey. J Affect Disord. 2011;129:380-4.

34. Kavanagh A, Priest N, Emerson E, Milner A, King T. Gender, parental education, and experiences of bullying victimization by Australian adolescents with and without a disability. Child Care Health Dev. 2018;44(2): 332-41.

35. Fenning RM, Baker JK, Baker BL, Crnic KA. Parenting children with borderline intellectual functioning: a unique risk population. Am J Ment Retard. 2007; 112(2):107-21.

36. Fenning RM, Baker JK, Baker BL, Crnic KA. Parent-child interaction over time in families of young children with borderline intellectual functioning. J Fam Psychol. 2014;28(3):326-35

37. Emerson E, Einfeld S, Stancliffe RJ. The mental health of young children with intellectual disabilities or borderline intellectual functioning. Soc Psychiatry Psychiatr Epidemiol. 2010;45(5):579-87.

38. Brown M. 1970 British cohort study. J Open Health Data. 2014;2(1):e6.

39. Elliott J, Shepherd P. Cohort profile: 1970 British birth cohort (BCS70). Int J Epidemiol. 2006;35:836-43.

40. Ketende SC, McDonald J, Dex S. Non-response in the 1970 British cohort study (BCS70) from birth to 34 years. Institute of Education, London: Centre for Longitudinal Studies; 2010.

41. Hacker E, Gatenby R, Killpack C, et al. Technical report of the 1970 British cohort study: 2008-2009 survey. London: NatCen; 2010.

42. TNS BMRB (undated) Technical report of the. British cohort study: age 42 survey (2012-2013). London: TNS BMRB; 1970. 
43. Butler N, Dowling S, Osborn A. 1970 British Cohort Study: Five-Year Follow-Up, 1975. [data collection]. 5th ed; 2016. UK Data Service. SN: 2699

44. Butler N, Bynner JM. 1970 British Cohort Study: Ten-Year Follow-Up, 1980. [data collection]. 6th ed; 2016. UK Data Service. SN: 3723

45. Bynner JM. 1970 British Cohort Study: Twenty-Six-Year Follow-Up, 1996. [data collection]. 5th ed; 2016. UK Data Service. SN: 3833

46. Centre for Longitudinal Studies. University of London (2016) 1970 British Cohort Study: Twenty-Nine-Year Follow-Up, 1999-2000. [data collection]. 4th ed. UK Data Service. SN: 5558

47. Centre for Longitudinal Studies. University of London (2016) 1970 British Cohort Study: Thirty-Four-Year Follow-Up, 2004-2005. [data collection]. 4th ed. UK Data Service. SN: 5585

48. Centre for Longitudinal Studies. University of London (2016) 1970 British Cohort Study: Forty-Two-Year Follow-Up, 2012. [data collection]. 2nd ed. UK Data Service. SN: 7473

49. Parsons S. Childhood cognition in the 1970 British cohort study. London: Centre for Longitudinal Studies UCL; 2014.

50. Emerson E, Hatton C, Baines S, Robertson J. The association between employment status and health among British adults with and without intellectual impairments: cross-sectional analyses of a cohort study. BMC Public Health. 2018:18:401.

51. Emerson E, Hatton C, Robertson J, Baines S. The association between employment status and health among British adults with and without intellectual impairments: cross-sectional analyses of a cohort study. SSMPopul Health. 2018;4:197-205.

52. Unit GT. Edinburgh Reading test. Sevenoaks: Hodder and Stoughton; 1978

53. Elliott C, Murray D, Pearson L. British ability scales. National Foundation for Educational Research, Windsor; 1978.

54. Rutter M, Tizard J, Whitmore K. Education, health and behaviour. London: Longmans; 1970.

55. Brimer MA, Dunn LM (1962) English picture vocabulary test. Educational Evaluation Enterprises.

56. Harris DB. Children's drawings as measures of intellectual maturity. New York: Harcourt, Brace and World; 1963.

57. Kalverboer AF. A profile test for the spatial-constructive development. Lisse: Switz \& Zeitlinger; 1972.

58. Schonell FJ. Reading and spelling tests. Edinburgh: Oliver and Boyd; 1971.

59. Rodgers B, Pickles A, Power C, Collishaw S, Maughan B. Validity of the malaise inventory in general population samples. Soc Psychiatry Psychiatr Epidemiol. 1999;34(6):333-41.

60. Mostafa T, Wiggins RD. Handling attrition and non-response in the 1970 British Cohort Study: CLS Working Paper 2014/2.Centre for Longitudinal Studies, London; 2014

61. Knol MJ, Le Cessie S, Algra A, Vandenbroucke JP, Groenwold RHH. Overestimation of risk ratios by odds ratios in trials and cohort studies: alternatives for logistic regression. CMAJ. 2012;184:895-9.

62. Zocchetti C, Consonni D, Bertazzi P. Relationship between prevalence rate ratios and odds ratios in crosssectional studies. Int J Epidemiol. 1997;26:220-3.

63. Chen C-Y, Lawlor JP, Duggan AK, Hardy JB, Eaton WW. Mild cognitive impairment in early life and mental health problems in adulthood. Am J Public Health. 2006;96(10):1772-8

64. Zetlin A, Murtaugh M. Whatever happened to those with borderline IQs? Am J Ment Retard. 1990;94(5):463-9.

65. Rutter M, Champion L, Quinton D, Maughan B, Pickles A. Understanding individual differences in environmental risk exposure. In: Moen $\mathrm{P}$, Elder $\mathrm{GHJ}$ Luschler K, editors. Examining lives in context: perspectives on the ecology of human development. Washington: American Psychological Association; 1995.

66. Nelson CA, Zeanah CH, Fox NA, Marshall PJ, Smyke AT, Guthrie D. Cognitive recovery in socially deprived young children: the Bucharest early intervention project. Science. 2007;318(5858):1937-40.

67. Chapman DP, Whitfield CL, Felitti VJ, Dube SR, Edwards VJ, Anda RF. Adverse childhood experiences and the risk of depressive disorders in adulthood. J Affect Disord. 2004;82(2):217-25.

68. McGee R, Williams S, Silva PA. An evaluation of the malaise inventory. J Psychosom Res. 1986;30:147-52.

69. Colvert E, Rutter M, Beckett $C$, et al. Emotional difficulties in early adolescence following severe early deprivation: findings from the English and Romanian adoptees study. Dev Psychopathol. 2008;20(2):547-67.

70. Hope S, Power C, Rodgers B. Does financial hardship account for elevated psychological distress in lone mothers? Soc Sci Med. 1999;49(12):1637-49.
71. Totsika V, Hastings RP, Emerson E, Berridge DM, Lancaster GA. Prosocial skills in young children with autism, and their mothers' psychological well-being: longitudinal relationships. Res Autism Spectr Disord. 2015;13-14:25-31.

72. Carson C, Redshaw M, Gray R, Quigley MA. Risk of psychological distress in parents of preterm children in the first year: evidence from the UK millennium cohort study. Open. 2015;5:e007942.

73. Wood N, Bann D, Hardy R, Gale C, Goodman A, Crawford C, Stafford M. Childhood socioeconomic position and adult wellbeing: evidence from four British cohort studies. PLoS One. 2017;12(10):e0185798.

74. Spinks R, McKirgan LW, Arndt S, Caspers K, Yucuis R, Pfalzgraf CJ. IQ estimate smackdown: comparing IQ proxy measures to the WAIS-III. J Int Neuropsychol Soc. 2009;15(4):590-6.

75. Sterne JA, White IR, Carlin JB, Spratt M, Royston P, Kenward MG, Wood AM, Carpenter JR. Multiple imputation for missing data in epidemiological and clinical research: potential and pitfalls. BMJ. 2009;338:b2393.

76. Shonkoff JP, Boyce WT, McEwen BS. Neuroscience, molecular biology, and the childhood roots of health disparities: building a new framework for health promotion and disease prevention. JAMA. 2009;301(21):2252-9.

77. Salvador-Carulla L, García-Gutiérrez JC, Gutiérrez-Colosía MR, et al. Borderline intellectual functioning: consensus and good practice guidelines. Rev Psiquiatr Salud Ment. 2013;6(3):109-20.

78. Public Health England (2015) The determinants of health inequalities experienced by children with learning disabilities. https://www.basw.co.uk/ system/files/resources/basw_24424-2_0.pdf Accessed 7 October 2019

79. Shahtahmasebi S, Emerson E, Berridge D, Lancaster G. Child disability and the dynamics of family poverty, hardship and financial strain: evidence from the UK. J Soc Policy. 2011;40(4):653-73.

80. Generalitat Catalunya (2017) Recommendations for caring for people with Borderline Intellectual Functioning. http://presidencia.gencat.cat/web/. content/departament/plans_sectorials_i_interdepartamentals/ funcionament_intel_lectual_limit/BIF-recommendations-GENCAT.pdf. Accessed 26 February 2018.

81. Finkelhor D, Shattuk A, Turner $H$, et al. Improving the adverse childhood Experiences Study Scale. JAMA Pediatr. 2013;167(1):70-5.

\section{Publisher's Note}

Springer Nature remains neutral with regard to jurisdictional claims in published maps and institutional affiliations.

\section{Ready to submit your research? Choose BMC and benefit from:}

- fast, convenient online submission

- thorough peer review by experienced researchers in your field

- rapid publication on acceptance

- support for research data, including large and complex data types

- gold Open Access which fosters wider collaboration and increased citations

- maximum visibility for your research: over $100 \mathrm{M}$ website views per year

At BMC, research is always in progress.

Learn more biomedcentral.com/submissions 